\title{
WILL BOTTLENECKS SLOW THE EXPANSION?
}

\author{
Wi11 jam D. Nordhaus
}

The topic of this conference is indeed an important one. Although currently the United States economy suffers from considerable excess capacity, both in labor and in product markets, we hope that this condition will not last forever. What I would like to discuss this afternoon is the state of utilization and the extent of imbalance in different markets, and possible strategivs for avoiding bottlenecks during this recovery.

The Legacy of the Recession

Starting roughily five years ago the world economy was struck by a series of shocks which culminated in the worst inflation, and thereafter the worst recession, of the post-war era. A simu?taneous boom in all the industrial countries led to severe capacity shortages in major industries, especially materials industries, following the 1973 boom, and the food and oil inflation that succeeded it, virtually every major industrial country suffered a severe recession.

The imbalances that developed in the boom of 1972-73, together with the devastating effects of the oil and grain shocks were enough to cause a downturn. But the fiscal and monetary authorities added their own restrictive influences. Thus, examining the OECD area:

Dr. Nordhaus is a member of the President's Council of Economic Advisers. 
o The narrowly defined money supply (M-1) decelerated from an annual growth rate of over 12 percent at the beginning of 1973 to below 7 percent at the end of 1974 .

- Since prices in the OECD were rising at approximately 13 percent annually, this means that the real money supply was falling at amost 6 percent per annum by the end of 1974 .

- As a result of the monetary stringency, short-term rates rose from around 6 percent at the beginning of 1973 to 11 percent in the second half of 1974 and long-tem rates rose about a point and a half.

- Fiscal policy turned sharply toward contraction after the 1973 boom. Real government expenditures from 1973 to 1974 rose only 1 percent in the United States and United Kingdom, 4 percent in Germany, and fell in Japan.

The effect of these forces is by now well known. One particularly disturbing legacy of the recession has been its effect on investment and thereby the level of capacity in the United States and abroad. Although measurement of capacity is quite difficult, the estimates show a significant decline in the growth of capacity in manufacturing industries over the last ten years. From 1948 to 1968, growth of capacity in manufacturing averaged 4.5 percent per year. From 1968 to 1973 , the growth rate dropped to 4 percent per year. But in the period from 1973 to 1976 , capacity grew at only 3 percent per annum. This means that over the last three years, the growth of capacity has not matched what we would need to keep up with potential output -- even with the most pessimistic of the estimates of potential that we have heard today.

Examining the latest data, we see that the growth in capacity leaves much to be desired, as is shown in Table 1 . 
TABLE 1.

Rate of Growth in Capacity 1976:2 to $1977: 2$

$\begin{array}{cc}\text { Manufacturing } & 2.8 \% \\ \text { Primary processing } & 3.2 \% \\ \text { Advanced processing } & 2.5 \% \\ & \\ \text { Materials } & \\ & \\ \text { Basic metal } & 1.4 \% \\ \text { Textile } & 2.7 \% \\ \text { Paper } & 3.0 \% \\ \text { Chemical } & 4.8 \% \\ \text { Energy } & 2.3 \%\end{array}$

For all of manufacturing the growth rate of the last year has been less than 3 percent, with basic metal materials showing the smallest increase and chemicals showing the most rapid.

It is clear that the recent slowdown in the growth of capacity must be reversed. We cannot hope to sustain a noninflationary expansion over the next three or four years, reaching high employment, without a major acceleration in the growth of capacity.

\section{The Current Imbalance in Labor and Product Markets}

Given the slow growth of capacity during the current recession, it is inevitable that an imbalance between labor markets and capital or product markets arises. To make more clear what the nature of this imbalance is, let us consider capacity output as it is distinguished from potential output:

- Potential output is conventionally defined as the level of output that would be produced at a reference unemployment rate, or weighted unemployment 
rate. In computing potential output, it has been conventional (up until recently) to assume that there are no capacity constraints. This can be rationalized by assuming that, through the accelerator principle on investment, the level of capacity adjusts with a distributed lag to the level of demand. If this is the case, and if labor is inelastically supplied, the ultimate constraint on output is labor input rather than capital.

- Capacity output can be viewed as the level of output Which can be produced with the current capital stock. clearly, the definition of capacity differs across industries, both because of flexibility of productive techniques in some industries and the possibility of shift work in others. Nevertheless, expecially in continuous processing industries, capacity has a definite meaning.

It is useful to compare the state of utilization of labor and product markets by looking at what will be called the full employment capacity utilization. To calculate the full employment capacity utilization index, we need to know the relation between capacity utilization and the level of unemployment. Then, using an "Okun's law for capacity," we can estimate what the level of capacity utilization would be if the unemployment rate were at "full employment." $1 /$ We have taken the "full employment" definition to be the weighted-average unemployment rate used in the CEA potential output series, this corresponding approximately to a 5 percent rate today.

We have investigated the relationship between these two series over the last twenty years, using a number of alternative techniques. Figure 1 shows the result of one of these experiments. According to this graph the period from the mid-1950s until the mid-1960s showed a gradual upward creep in the full employment capacity utilization index. Then starting in 1965 and lasting until approximately 1970, there was a 


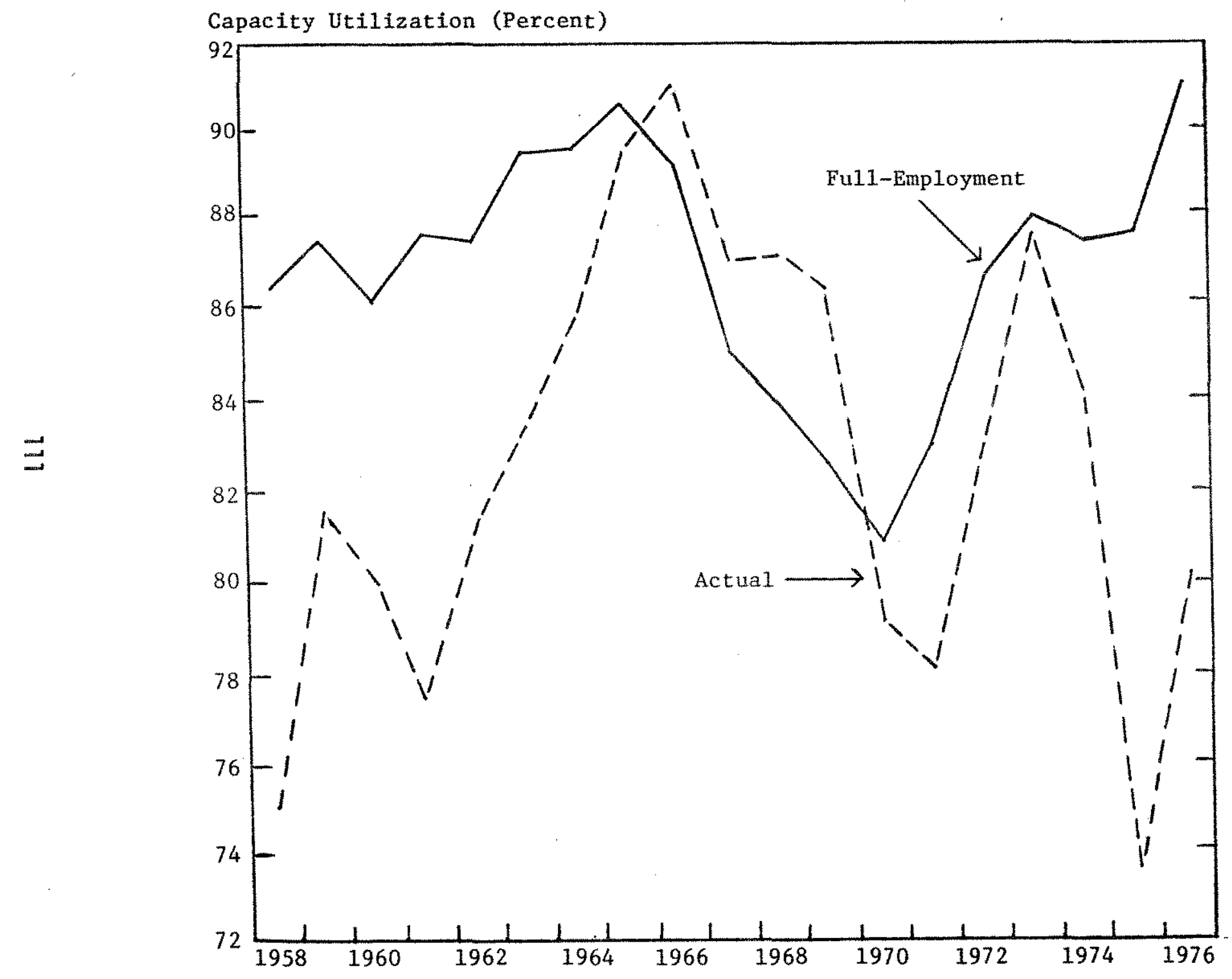

Figure 1. Actual and Ful1-Employment Capacity Utilization (Federal Reserve Index) 
dramatic decrease in this, reflecting the potency of the investment boom of the 1960s. Starting in 1970, however, there was a definite and sharp upward rise in the full employment capacity utilization index. Over the last six years full employment capacity utilization has risen from approximately 81 percent to the current level of 91 percent.

The full employment capacity utilization index is an indication of how tight product markets in manufacturing would be, today, if we were at full employment (and potential output as defined above). These can be compared with historical experience. The capacity utilization rates of the Federal Reserve Board, which we are using here, averaged about 33 percent for manufacturing for the period 7955 through 1975, and about 86 percent for industrial materials from 1967 through 1975. The highest level of the capacity utilization index for manufacturing which has been experienced for an entire year since 1948 was 91 percent in 1966. The most recent period of high utilization was in 1973 . In that year capacity utilization in manufacturing averaged 88 percent, while primary processing industries had a utilization rate of 92 percent.

What are the implications of this apparent rise in the fult employment capacity utilization index? The obvious point is that we cannot expect to have high levels of employment without one of the three following possibilities: 1) a significant investment boom; 2) a major change in the composition of our output away from manufacturing and materials; or 3 ) operating rates in manufacturing and materials which are well above those which are normally experienced. 
Or put differently, it is clear that if the capacity and utilization data of the Federal Reserve Board are relatively accurate, then there is currently insufficient capacity to sustain an inmediate gallop to full employment.

Returning to our earlier discussion, we noted that one of the most significant bequests of the recent recession was insufficient investment. Before the recession got underway, our index was considerably lower: thus in 1973 the full employment capacity utilization index was 88 percent, 3 percent lower than it stands today. The investment slump and associated problems of the last three years have apparentiy raised our full employment capacity utilization index three full points.

\section{The Break-even Capacity Utilization}

Why has the growth of capacity not kept up with the growth of potential output? This is the other side of the question, "why has investment lagged so badly during the current recession and recovery."

CEA has studied the reasons behind the investment lag, using a number of economic theories of investment. Although different models give different answers, the basic reason -- and one that can hardly be surprising - - is that the demand for future capacity is performing poorly because the level of utilization of today's capacity has been so low. There are other factors as we11 -- environmental regulations certainly have raised the cost of additional capacity in many heavy industries (steel, utilities, and chemicals being among the most 
heavily affected). In addition, the depressed state of the stock market hardly is conducive to new ventures, al though -- to be sure -stock market prices (and in particular the ratio of market value to replacement costs, Q) have reflected quite closely levels of utilization of capacity over recent years. Finally, there has been a clear shift in the composition of investment away from long-lived investments -- especially structures -- and toward equipment. Nonwithstanding the caveats, however, it is probably the case that the major reason for the depressed state of investment is the low levels of capacity utilization the economy has experienced over the last three years. We know that very low levels of utilization -. operating through the accelerator mechanism -- lead to a slowdown in investment and in the growth of capacity. If capacity is below some "break-even" point, and investment therefore insufficient to keep capacity growing rapidly enough, we may actually be in the situation where capacity is growing less rapidly than potential output. The full employment capacity utilization rate would therefore rise and the imbalance between labor and product market would widen. It is ironic that in pursuing an anti-inflation policy which keeps the level of slack in the economy very high, we have created a situation in which future bottlenecks become more likely.

As a way of illustrating the relation between the growth of capacity and capacity utilization, we have run a standard investment equation. The equation relates the level of investment to the rental cost of capital and non-linearly to the level of capacity utilization. 
Then by taking into account the historical relation between investment and capacity growth, we can ask whether the level of capacity utilization has been sufficiently high to assure that capacity growth is as rapid as potential output.

Figure 2 shows a graphic representation of the relation between capacity utilization and capacity-potential difference, In making this relationship, we have assumed that the real cost of capital (in terms of percent per annum) was at its post-war average, so that there was no extraordinary push or pull from monetary or fiscal incentives. The figure shows quite clearly that the difference between the growth of measured capacity and potential output is positively and nonlinearly related to the appropriately lagged rate of capacity utilization.

One can calculate from such a relationship, assuming no change in the historical level of capacity utilization at which the capital stock has grown at the same rate as potential output, the break-even utilization rate. This presumes, as has been the case recently, that -- if imbalances are not to appear -- potential output will grow approximately 1.2 percent per annum faster than the capital stock.

According to these relationships, the break-even capacity utilization point is around 84 percent. That is to say, when capacity utilization is 84 percent, and assuming the relationship is the same as in the historical period, capacity output will be growing as rapidly as potential output. On the other hand, if utflization is lower than this ... say the 74 percent in 1975 or 80 percent in 1976 -m 


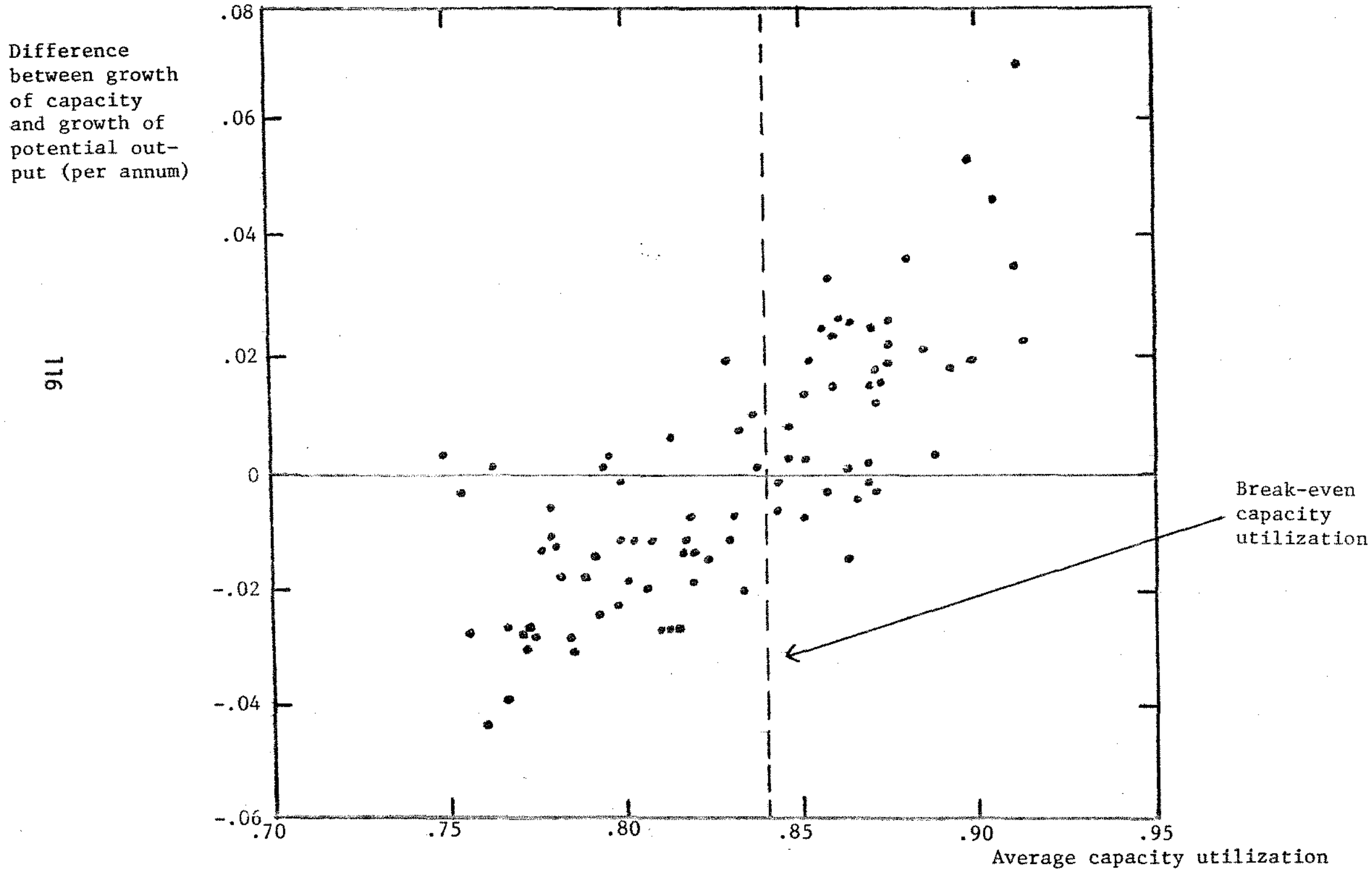

Figure 2. Relationship between lagged average capacity utilization and the growth of capacity relative to potential output, 1955-76. The level of capacity at which capacity and potential output grow at the same rate ("break-even capacity utilization") is estimated to be 84 percent. 
incentives to invest are insufficient to keep the capital stock growing as rapidly as potential output.

It appears that even today we are below the break-even point, for over the last few months capacity utilization in manufacturing has been averaging only 83 percent.

To summarize the evidence up to date: we are faced with a paradoxical situation. Capacity output has been growing more slowly than potential output for some time now. Yet, we are constrained from having a rapid growth in actual output because of the fears in many quarters of getting too close to the inflationary shoals. On the other hand, if we stay too far away from our objective of high levels of employment and utilization, we see that capacity will grow too slowly for us to reach our ultimate target. Thus, again according to historical relationships, if we were to stay at a utilization rate of 83 percent for an extended period of time, our full employment capacity utilization index would continue to rise.

\section{Speed Limits to Growth?}

We have seen that there is a fundamental dilemma which the economy faces over the next four years. A path of immediate recovery will clearly lead the economy onto the shoals of capacity bottlenecks. On the other hand, a path of very slow growth, with capacity utilization below the break-even point, will lead to an increasing secular divergence between potential output and capacity output. Clearly the optimum lies somewhere in between. 
The problem is what I will somewhat whimsically call the flypaper problem. A hungry fly sees a delicious morsel of fiy food across the room, but unfortunately the morsel is very close to a sticky piece of flypaper. The fly wishes to get as much of his tasty dinner as he can, but in doing so he risks the danger of overshooting his dinner and getting stuck on the flypaper.

of course the flypaper problem is exactly the problem we have been discussing up to now. If we stay too far away from potential output and capacity in the hopes of avoiding the inflationary shoals, we will indeed not risk present inflation, but we are risking future inflation by building insufficient capacity to prevent future bottlenecks. On the other hand, if we pursue the strategy of immediate recovery, we risk encountering inflationary bottlenecks immediately, if we encounter exogenous disturbances which lead us to overshoot capacity and trigger inflation. Therefore, like our friendly fly, we must get close enough to capacity to get investment, output, and employment high, but at the same time not overshoot our target.

\section{Strategies for The Recovery}

Given our current economic situation -- high levels of unemploy ment and the high level of the full employment capacity utilization rate -- this suggests a strategy for the recovery must take into account both factors.

- We must assure producers that they will have adequate markets to se11 their output. This implies that the levels of capacity utilization must be above the break-even point -- and soon. 
The problem is what I will somewhat whimsically call the flypaper problem. A hungry fly sees a delicious morsel of fly food across the room, but unfortunately the morsel is very close to a sticky piece of flypaper. The fly wishes to get as much of his tasty dinner as he can, but in doing so he risks the danger of overshooting his dinner and getting stuck on the flypaper.

of course the fiypaper problem is exactly the problem we have been discussing up to now. If we stay too far away from potential output and capacity in the hopes of avoiding the inflationary shoals, we will indeed not risk present inflation, but we are risking future inflation by building insufficient capacity to prevent future bottlenecks. On the other hand, if we pursue the strategy of immediate recovery, we risk encountering inflationary bottlenecks immediately, If we encounter exogenous disturbances which lead us to overshoot capacity and trigger inflation. Therefore, like our friendly fly, we must get close enough to capacity to get investment, output, and employment high, but at the same time not overshoot our target.

\section{Strategies for The Recovery}

Given our current economic situation -- high levels of unemployment and the high level of the full employment capacity utilization rate - this suggests a strategy for the recovery must take into account both factors.

- We must assure producers that they will have adequate markets to sell their output. This implies that the levels of capacity utilization must be above the break-even point -and soon.

- At the same time we must recognize that our 1 abor and pro- 
- duct markets are badly out of balance. This means that our recovery must proceed in an orderly fashion as investment accelerates and capacity output recovers its growth.

- The imbalance between capacity and potential output must be taken into account in our overall fiscal and monetary policy. It would be extremely untimely for the monetary authorities to slam on the brakes at that point when we so badly need investment. And our fiscal and tax poticy must recognize the central importance of special incentives to invest during the next few years.

This last consideration is the one on which I would like to close. As I have indicated today, our capacity output does not dovetail with the social and economic needs of today. In designing the major fiscal policy actions over the next two years, we must taken into account the needs for capacity expansion. The Administration is considering carefully the possibility of giving special incentives for investment in the short-run to aid the growth of capacity.

It should be emphasized that a white it is always nice to have additional capacity - the needs over the next few years are particularly critical. If we are to succeed in reaching a noninflationary ful1 employment econony, we must assure that capacity expansion proceeds at a sufficient pace. I expect that the Administration will propose tax measures especially designed to encourage the growth of capacity over the next few years. We hope that a climate of cooperation from the monetary authorities and the business comunity will make sure that, in fact, capacity bottlenecks do not slow the current recovery.

\section{Footnote}

I/ Note that the calculation is a "straight up" increase in output and utilization, like that customarily employed in calculating the "gap." 